\title{
Usar la palabra para volver a narrar: la relación arte-literatura en la obra de Jaume Plensa
}

\author{
Cintia Gutiérrez Reyes \\ Universidad de Málaga \\ c.gutierrezreyes@gmail.com
}

RESUMEN: La cuestión de la autonomía del arte respecto a la literatura ha supuesto un continuo debate en el mundo del arte. En este artículo ${ }^{1}$ tratamos la relación entre arte y literatura y cómo Jaume Plensa plantea una nueva ilación donde la obra de arte no pretende ser mera imagen auxiliar del texto que la inspira. En este contexto, hemos analizado las obras del escultor catalán en relación a las fuentes literarias de que las parten, tratando de desvelar los distintos caminos de representación escultórica que estos relatos han forjado dentro del imaginario de Plensa.

PALABRAS CLAVE: Arte contemporáneo; Imagen y palabra; Jaume Plensa; Escultura contemporánea.

\section{Using Words to Recount: the Relation between Art and Literature in the Work of Jaume Plensa}

ABSTRACT: The question of the autonomy of art in relation to literature has been an ongoing debate in the art world. In this article we discuss the relationship between art and literature, and how Jaume Plensa raises a new point where the work of art does not intend to be an auxiliary image of the text that inspires it. In this context, we have analyzed the works of the Catalan sculptor in relation to its literary sources, trying to reveal the different paths of sculptural representation that these stories have forged within the imaginary of Plensa.

KEYWORDS: Contemporary Art; Word \& Image; Jaume Plensa; Contemporary Sculpture.

Recibido: 25 de abril de 2017 / Aceptado: 29 de junio de 2017.

\section{La cuestión de la autonomía del arte}

La cuestión de la autonomía del arte respecto a la literatura afecta a la propia línea de flotación del estamento artístico, supuso una sacudida y alcanza su apogeo en la crisis perpetua que desencadenaron, y que sigue de actualidad, la proposición atribuida a Horacio, ut pictura poesis, y las supuestas palabras de Simónides de Ceos en las que declaraba que la pintura sería poesía muda y la poesía una imagen que habla. Este análisis, que prolonga una tradición crítica que se acerca al estudio de la relación entre las artes a partir del principio de rivalidad o subordinación de unas en relación con las otras, según cuáles eran sus virtudes técnicas para representar la realidad, ha supuesto una de las cuestiones centrales en el discurso sobre arte y concierne no menos a la literatura. Mario Praz, excelso crítico y esteta de renombre, plantea una comparación sin igual entre las artes: «[...] desde épocas remotas ha existido una mutua comprensión y una correspondencia entre la pintura y la poesía, y podríamos añadir que entre la literatura y las artes» (Praz, 1997: 9). Es, por lo tanto, una asociación que traduce un código semiótico a otro. Una relación ecfrástica cuyo caso, por excelencia, podemos rastrear desde el canto XVIII de la llíada de Homero, en el que se describen las imágenes que Hefesto representó en las armas de Aquiles encargadas por Tetis. Y es que el diálogo o convivencia entre imagen y letra prevista por la tradición se perpetúa durante siglos en una

Cómo citar este artículo: GUTIÉRREZ REYES, Cintia, "Usar la palabra para volver a narrar: la relación arte-literatura en la obra de Jaume Plensa", Boletín de Arte-UMA, n. 38, Departamento de Historia del Arte, Universidad de Málaga, 2017, pp. 97-108, ISSN: 0211-8483, DOI: http://dx.doi.org/10.24310/BoLArte.2017.v0i38.3259 
"convención icónica», como la llama Hagstrum (1974). «La relación del lenguaje con la pintura es una relación infinita», como afirma Foucault (1968: 19). Pensemos, por ejemplo, en los jeroglíficos egipcios o en las leyendas en forma de ancilas que acompañan a las figuras representadas durante la antigüedad y en la Edad Media, y que identificaban al retratado. Esta relación entre la obra de arte y la lectura, a la que la cultura occidental nos tenía acostumbrados, va a estar vigente también en las vanguardias. Como afirma Matas Pons (2014: 243): «Es cierto que la contemplación de la obra de arte siempre fue inseparable de la lectura. En el emblema, por ejemplo, cuando el proverbio moral acompañaba al dibujo que lo ilustraba. [...] Incluso en los cuadros del surrealismo, pues el texto escrito sobre el lienzo es una hermética glosa de la imagen figurativa a la que acompaña, como la conocida pipa de Magritte». En todos estos ejemplos, los signos escritos estaban ahí para ser leídos, como representación de lo verbal.

Para despertar de la ilusión de realidad, en la que la escritura y la pintura se divorcian, debemos adentrarnos prácticamente en el siglo XX, cuando según Tua Blesa (2011: 98): «los signos lingüísticos que se representen no significarán otra cosa fuera de ellos mismos. En el arte conceptual, la escritura deviene el único objeto de representación y desplaza del espacio plástico cualquier otro objeto que no sea la lengua y sus signos gráficos». Un universo indómito de caos y signos sin domesticar que nos ha dejado desamparados del vestido racional, y la lectura de un tumulto casual y arbitrario de signos escritos que no remiten a ningún orden alfabético, amenaza el valor regulador del significante. Por tanto, para acometer sin subterfugios la lectura de la imagen visible, debemos convertirnos en parte activa del proceso de creación.

Esta nueva posición de la obra de arte como campo abierto para un espectador emancipado, retoma las palabras de Eliot (2004: 20) sobre que «el autor será más perfecto cuanto más separados estén en él, el hombre que sufre del que crea», y a continuación realza, como recuerda Maite Méndez (1992: 31), «el papel creativo del espectador al contacto con la obra de arte que, al descifrarla e interpretarla, añade su contribución al proceso creativo».

Este nuevo encuentro entre la obra y su lectura, en el que la muerte del autor es necesaria como peaje para el nacimiento de un nuevo espectador, entra dentro de las previsiones que el mismo Derrida hizo al desarrollar su concepto de deconstrucción, pues con él vaticinaba cómo «la estricta materialidad del significante es el único valor regulador y que, por tanto, se hace necesario admitir una ilegibilidad radical que excede cualquier significado que se presente como estable y desborda cualquier sentido que se quiera unívoco» (Blesa, 2011: 74).

Es, por tanto, en esta mudez del signo escrito donde posicionamos la obra de Jaume Plensa, cuya propuesta excede cualquier valor regulador o desborda lo libresco. El autor analiza el signo visual según las estrategias del propio acto de lectura. De este modo, construye «un interregno entre el mundo plástico y la cosmovisión literaria» (Hernández León, 2006: 6). Un estadio liminal que bascula entre la materia y su significado literario. Un escindir que merodea por la obra literaria para extraer su esencia y buscar la capacidad epitelial u objetual de lo narrado, y con ello desvelar la verdad de un espacio impensado. Un espacio en el que se disponen las esculturas y las piezas hechas con textos, para el que Plensa demanda un tipo de lectura en el que participan todos los sentidos. En estas esculturas, el libro, recipiente de la escritura por antonomasia, se encuentra derramado, expulsado, para invadirnos, un lenguaje expandido de referencias literarias encabalgadas en la linde.

\section{Jaume Plensa: la palabra y su sombra}

En Los pasos perdidos de Alejo Carpentier, el protagonista, huérfano de nombre, se afana en introducirse en la selva para encontrar el grito primordial que encierra el hueco sonoro de todas las potencias de un mundo en el día inaugural de su expansión (Garrido, 2000: 6). Esta búsqueda incesante que lleva siempre a encontrarse con uno mismo, se halla patente en la obra de Jaume Plensa, un autor que plantea la cultura universal como factor fundamental de su universo representado. Como afirma Alfredo Taján (2000: 9), «el uso que el artista hace de la palabra no delimita la innegable dimensión lírica de un texto materializado, sino que lo catapulta a una esfera casi áurea».

Establecer un corpus de referencias literarias en la obra de Jaume Plensa supone deshacer la madeja y adentrarnos en un laberinto donde los recovecos del espacio se tornan reconocibles a primera vista, para desvelar la esencia de una historia que vincula lo leído con lo recordado. Como 
afirma William Jeffett (2007: 45): «Plensa nos dirige hacia la suspensión del juicio frente a la contradicción vivida». «Shakespeare, Blake o Estellés me han ayudado a formarme», afirma Plensa (Rendueles, 2007: 44). Ese corpus constituye aquello que Harold Bloom (2007) denominó como La angustia de las influencias.

Sin embargo, cuando Plensa inscribe versos de los autores citados en su obra plástica lo de menos es el significado. «Quien se detenga en ellas y las utilice para descansar [...], se quedará sordo para lo que la obra le está susurrando, sin embargo, aquellos que se limiten a atender sus rumores y a descodificarlos como signos inmediatos, como huellas todavía cálidas de algo que acaba de pasar por aquí y que, si lo miramos bien somos nosotros mismos» (Aguado, 2000: 48). Pero Plensa, en su búsqueda de inspiración, también escribe sus propias poesías sobre arte, algo que confirman las reflexiones de Claudio Guillén (2005: 124): «[...] el centro de gravedad sigue siendo la literatura».

«La obra de Plensa -subraya Daniel Abadie- entronca con la Gran Obra, con la voluntad mallarmeana del Libro, con ese empeño en que el trabajo del artista refleje una escena original, olvidada, pero cuya ausencia es todavía perceptible» (cit. en Castro, 2007: 47). Sin embargo, Plensa (2008: 47) advierte que su obra trata de hacer patente el silencio: «el silencio es un deseo, un sueño, un aspiración, algo tan desconocido e inaccesible, que tan solo podemos imaginarlo». Quizá, en el caso de Plensa, se deba a que el concepto que él sostiene de silencio es el que emana de los textos de Sontag, Cage o de Octavio Paz, un silencio que se torna quimera por la sonoridad que emiten los órganos de nuestro propio cuerpo. «Tan pronto todo está en calma y queda callado, cuando creemos haber logrado el silencio, descubrimos que interrumpe algo tan próximo como nuestro propio cuerpo. Nuestro ruidos del cuerpo» (Plensa, 2008: 47).

Para hacernos partícipes de nuestro sonido, Plensa construye sus cabinas, Selfportrait I, II, III, 1997 y Waiting Room, 1997 [1] o Seven Deities of Good Fortune, 19992000 [2], un lugar de meditación donde participamos de un ritual necesario para encontrar la serenidad; «nada nos viene de fuera», escribe Vila-Matas (2009: 7). Siempre resulta curioso el discurso como lugar para pedir silencio. Sin embargo, Plensa se alimenta de esta «épica de contrarios» (Taján, 2000: 10). Un mundo de contradicciones donde apreciamos

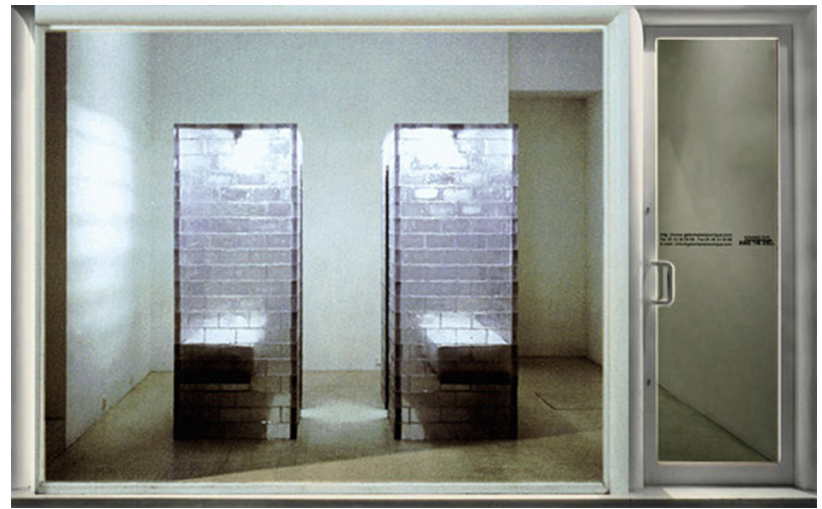

1. J. Plensa, Waiting Room, 1997, (C) Galerie-Pieceunique (http://galerie-pieceunique.com/exhibitions/jaume-plensa/)

la peculiar poética de la descontextualización. La obra escultórica de Plensa, mantiene Bárbara Catoir (2000: 136), «se articula a través de contrastes: extensión y estrechez, movimiento y permanencia estática, oscuridad y claridad, pero sobre todo sonido y silencio». Como advierte Blake, sin contradicción no hay progresión: «Atracción y repulsión; Razón y Energía; Amor y Odio, son necesarios para la existencia humana» (cit. en Castro, 2007: 47).

Llegados a este punto, debemos afirmar que William Blake supone para el escultor catalán un hito casi parental en el desarrollo de su discurso. Para William Blake «un

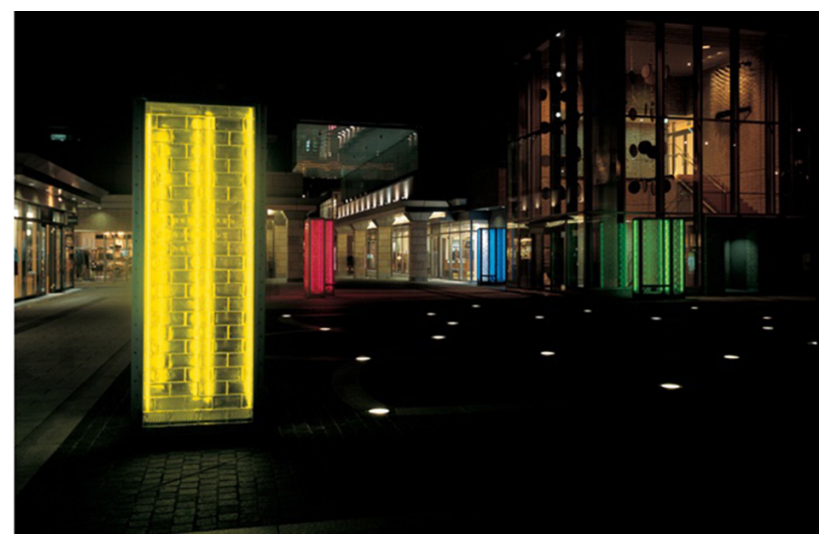

2. J. Plensa, Seven Deities of Good Fortune, 2000, @Tamada Projects. (http://www.tamada-pj.co.jp/art/artist/plensa_pub_en.html) 


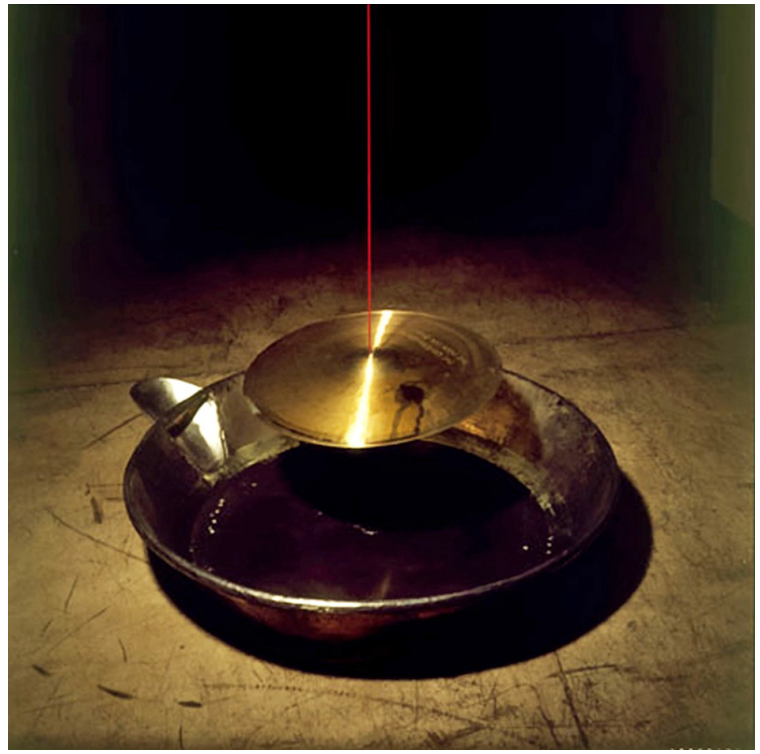

3. J. Plensa, Rumor, 1997, ( $)$ tdm+ (http://t-dm.com/jaume-plensa-rumor/)

pensamiento llena la inmensidad» (Plensa, 2008: 47). Este aforismo de la plancha octava de los Proverbios del infierno fue grabado en la pieza Rumor, 1997 [3], una obra que se construye mediante un platillo de gong suspendido de un hilo color rojo por el que desciende una gota de agua. Su intención era llenar el espacio con una sola pieza que emitía un sonido rotundo. Este sonido es aleatorio como lo puede ser la lectura de los Proverbios del infierno, sin orden y con la rotundidad que prolifera en sus versos.

Según las palabras del propio Plensa, la habitación donde se ubica el címbalo representa la inmensidad del cosmos y, de esa inmensidad, cae una gota de agua que representa la caída del hombre del paraíso según la filosofía gnóstica de William Blake. Ese hombre que cae golpea las palabras y vuelve a convertirse en sonido que llena la inmensidad (Terrasa, 2005: 41). Esta obra que en principio se componía de un címbalo ha ido en aumento, siendo uno de los sellos de identidad del autor. Ya en enero del 2000 la obra se componía de 21 címbalos para la exposición del Palacio de Velázquez en Madrid; y en 2002 de 41 címbalos en la iglesia de Pollença, a la espera de la obra definitiva que constará de los 73 proverbios del infierno grabados sobre las placas de bronce (Ballesteros, 2014: 90). Cabe precisar que los címbalos son de diferentes diámetros, de modo que se mezclan tres notas distintas percutidas a intervalos regulares, gota a gota. El resultado global es aleatorio, marcado por el ritmo interno de cada uno de los címbalos, por la posición del espectador en el espacio y por la cantidad variable de palabras grabadas en cada uno de los címbalos. Es decir, la cantidad de palabras repercute de manera exponencial en la densidad del metal y el sonido se ve alterado. «Por tanto, existe una correspondencia biunívoca entre el aumento del número de letras y la altura sonora, y no hay yuxtaposición de un texto poético y una tapa de bronce, sino simbiosis entre ambos» (Terrasa, 2005: 47). «El corazón del grabado. Aún debo aprender a vivir sin él» (Plensa, 2008: 63). Esta modificación física es esencial para el autor e imperceptible para el espectador, por lo que esta obra se compone de dos sensaciones, dos fases en la relación con ella, la percepción sonora y plástica, y después la literaria. De esta forma, apunta Consuelo Císcar (2007: 19): «lejos de pretender hacer una obra cerrada y conclusa en sí misma, Plensa prefiere dejar que sea el propio espectador quien la complete, estableciendo un diálogo con ella, cuyos lejanos ecos y susurros quizás parezcan contradictorios desde diferentes perspecti-

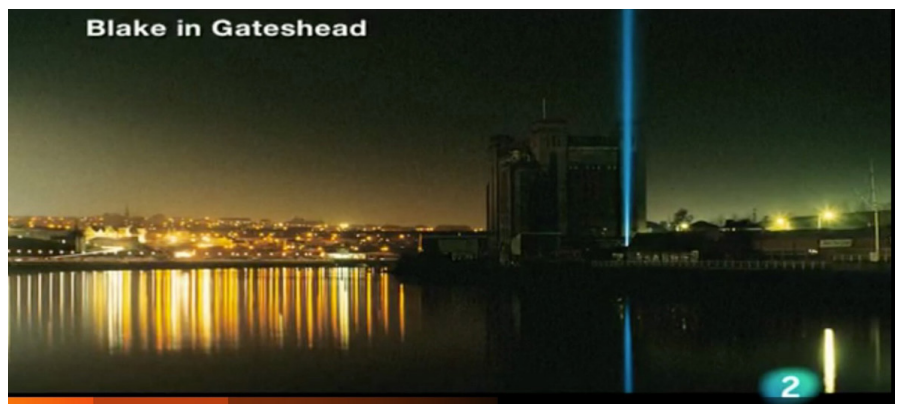

4. J. Plensa, Blake in Gateshead, (C) RTVE. (http://www.rtve.es/television/20140314/ escultura-arte-jaume-plensa/369598.shtml) 
vas». Finalmente esta obra se concluirá en Voces del mundo, una pieza de 196 címbalos que representará a todos los países (Ballesteros, 2008: 34).

El caos ordenado de Blake ha cumplido una innegable función en la génesis creativa del escultor catalán, muestra de ello es la obra Blake in Gateshead, 1996 [4]. Esta pieza, ubicada en el norte de Inglaterra, fue realizada con motivo de la transformación de una antigua fábrica de grano en museo. Basada en la idea de que la materia es un punto de partida y que la luz llena el espacio puesto que es inaprensible (Ballesteros, 2008: 50), supone una pieza clave para entender el aforismo de la plancha seis-siete «No hay pájaro que vuele muy alto si lo hace con sólo sus alas» (Blake, 2007: 227). La pieza se construye en un estado bisagra entre sus obras de luz y los gong. En ella, coloca un anillo de bronce al que le graba la frase antes expuesta. En el centro de este, se ubica una luz que emana hacia el cielo sin un fin determinado, lo que hace que la fábrica que se encuentra a orillas del Time quede fundida con el resto del paisaje. La arquitectura contiene al mismo tiempo materia y espíritu, y Blake es el puente entre el cielo y la tierra, vinculando Newcastle y Gateshead.

En toda la influencia de Blake en la obra de Plensa se refleja una dialéctica entre lo individual y lo colectivo, entre la palabra, su significado material y abstracto. En sus años de trabajo en una fundición de hierro, mientras observaba el hierro fundido a $2000 \mathrm{C}^{\circ}$ con su característico color rojo que asemejaba una acuarela sin retoques, el escultor catalán pensó en la luz como parte de la materia (Plensa-Drathen, 2008: 23).

Otro grupo de obras que se basan en esa idea del aforismo de la plancha seis-siete, «No hay pájaro que vuele muy alto si lo hace con solo sus alas» (Blake, 2007: 227), son sus retratos o cabezas esculpidas. De este grupo distinguimos tres tipos de piezas: los retratos de alabastro, los retratos hechos de palabras y las cabezas con luz.

La metáfora que vincula la cabeza con la figura del pájaro simboliza la creencia del propio autor: mientras la cabeza está aquí, los pensamientos pueden volar muy alto (Patrick, 2008: 178). Este grupo iconográfico relaciona el cuerpo con la cárcel, donde hay un alma a la que hay que llegar de una forma casi geográfica, una idea extraída del pensamiento frenológico del vienés Franz Joseph Gall. Esa idea de cárcel del cuerpo para el alma, de origen platónico, aparece en la larga tradición de la poesía mística española, como en la poesía de Teresa de Jesús:

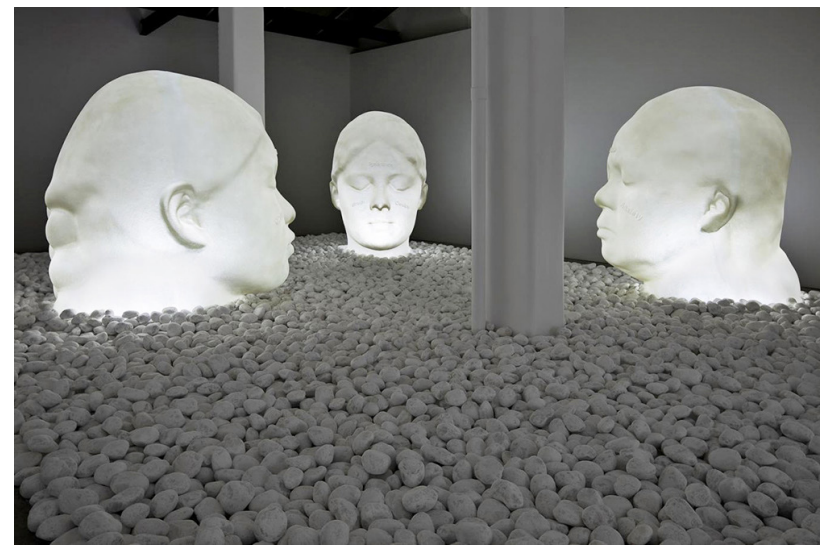

5. J. Plensa, Dialogue, 2009, (C Galería Senda. (http://galeriasenda.com/artista/jaume-plensa/)

\begin{abstract}
¡Ay, qué larga es esta vida!
¡Qué duros estos destierros, esta cárcel, estos hierros

en que el alma está metida!
\end{abstract}

Así mismo, recurre a esta misma idea gracias a la carta de Oscar Wilde al director del Daily Chronicle, publicada como «La reforma de las cárceles», y recogida en el volumen El hombre y la cárcel (2009: 154-155): «A primera vista hay tres castigos permanentes, autorizados por la ley en las cárceles inglesas: 1) el hambre; 2) el insomnio y 3) la enfermedad». La representación fáctica en la obra de Plensa son tres cabezas enfrentadas y en posición de meditación [5]. Esta imagen, que evoca mediante la iconografía de las tres gracias la obra literaria de Wilde, representa los martirios a los que un individuo debe enfrentarse en la cárcel. «Nunca nadie ha visto directamente su propio rostro. El rostro no es para uno mismo sino para el otro [...] Un rostro es una puerta a la que siempre llamamos» (Plensa, 2008: 91). Esos semblantes del otro que nos interpelan derraman su inquietud de ser reconocidos por quien los mira, como advierte Plensa; y siguiendo a Gabilondo (2000: 156): lo que ahora contemplamos es cómo cada cuerpo singular se convierte en un rostro público.

Pero no solo el rostro del otro es estetizado en la obra de Plensa. El autor catalán se autorretrata de forma continuada, quizá porque como advierte Aguado (2000: 50): «El que sale de sí para pasar unos segundos entre el cristal y el 


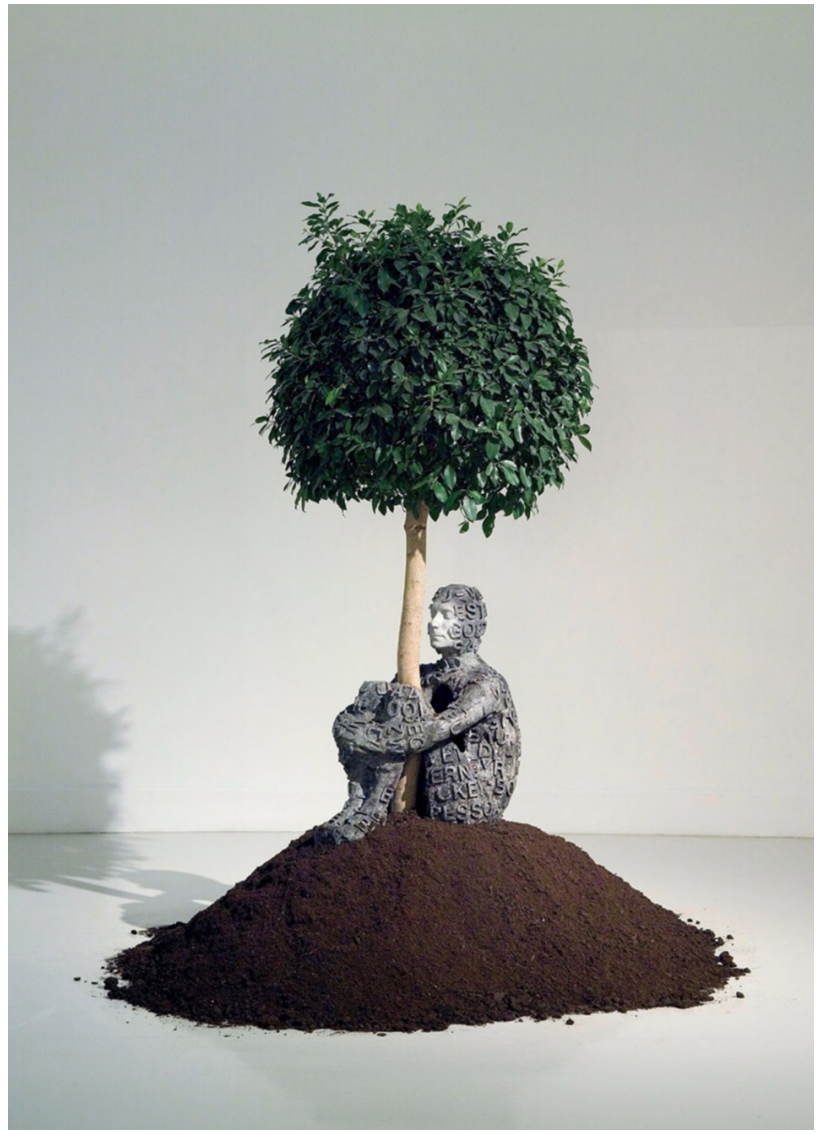

6. J. Plensa, Autorretrato con árbol, 2005, @ CAC Málaga. (http:// jaumeplensa.com/exhibitions-and-projects/exhibitions/jaume-plensa-cac)

azogue de un espejo lo más probable es que regrese a su yo malcosido". "¿Cómo romper los espejos y alcanzarte?», escribe Plensa a propósito de la obra Macbeth de Shakespeare (2008: 24). Unas palabras que se materializan en la obra Autorretrato con árbol, de 2005 [6]. Shakespeare relata cómo un ejército disfrazado con ramas avanzaba hacia el castillo, de tal forma que el bosque caminaba hacia el edificio. Las brujas vaticinan a Macbeth (2006: 1241-1242): «[...] pues ningún hombre dado a luz por mujer a Macbeth podrá dañar» y «Macbeth nunca caerá vencido hasta el día en que el gran bosque de Birnam suba para combatirle hasta la alta colina de Dunsinan».

Macduff, Malcolm y el inglés Siward, conde de Northumberland, atacan el castillo de Dunsinane, con un ejército camuflado con ramas del bosque de Birnam, con lo que se

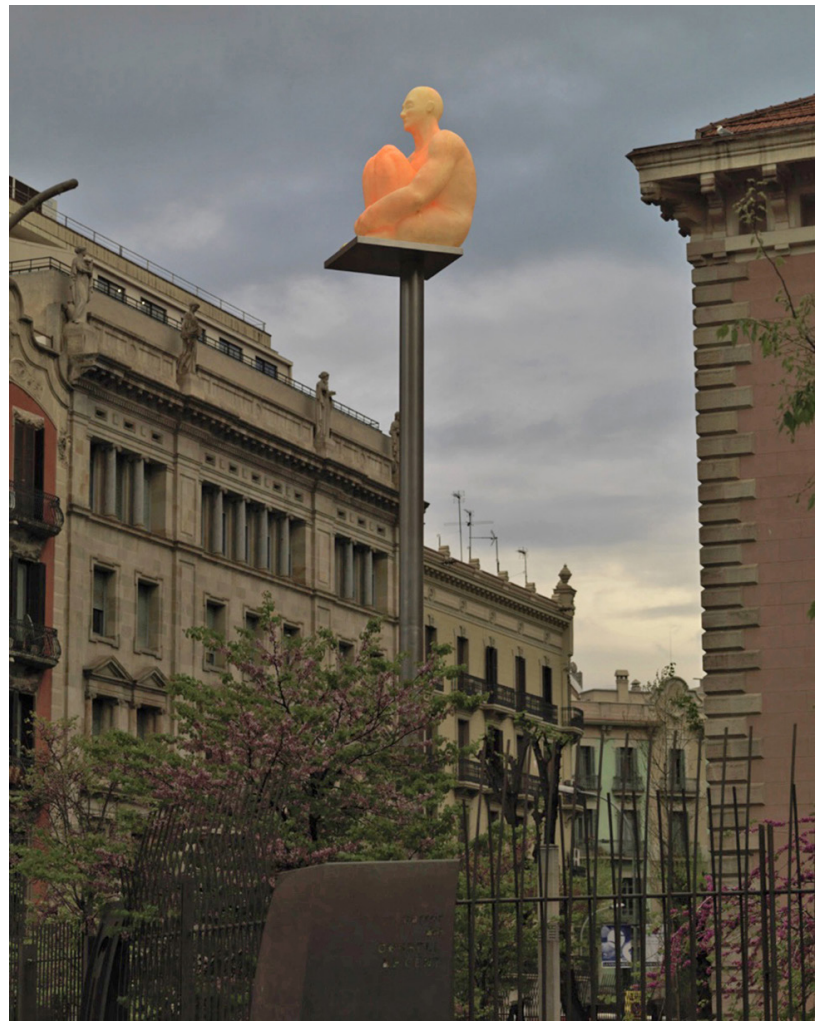

7. J. Plensa, La Llarga Nit, 2007, @ jaumeplensa.com. (http://jaumeplensa.com/exhibitions-and-projects/exhibitions /jaume-plensa-barcelona)

cumple una de las profecías de las brujas: «[...] el bosque de Birnam se mueve y ataca Dunsinane».

Los Autorretratos con árbol, 2005, responden a la simbología del alma como árbol filosófico, que al renacer de la materia muerta hunde sus raíces en la tierra para alcanzar con sus ramas el cosmos. Según Plensa «somos demasiado rígidos, somos demasiado corpóreos y esto hace que el alma se ahogue» (cit. en Patrick, 2008: 180). Realmente, la idea del árbol representa el crecimiento del alma prescindiendo del cuerpo. Esta relación con la figura del árbol se une iconográficamente con la historia de Adán y Eva, una constante en obras de poetas coetáneos de Shakespeare como John Milton y su Paraíso perdido (2002: 405).

No será la única iconografía en la que nuestro autor utilice las Sagradas Escrituras como fuente primaria de inspiración para la creación de sus piezas. En las piezas de- 
nominadas La llarga nit, 2007 [7], en las que Plensa suele introducir luz, representan la idea de ángeles kafkianos o gárgolas que, como faros, nos iluminan pero no pueden subir más, están atrapados por su propia condición (Corá, 2005: 39). Ángeles caídos que remiten a Blake, Kafka, Wilde e incluso a las Sagradas Escrituras o el Evangelio de San Juan. Estas obras de una figura iluminada colocada sobre un poste de 12 metros y situada por encima del nivel visual del espectador tienen la función de faro que invita al espectador a hacer un viaje poético. La figura del hombre en posición fetal, en una columna de 12 metros, es la representación de la figura iconográfica de los estilitas que vivían retirados en columnas y a los que las gentes del pueblo llevaban alimentos mientras ellos miraban al infinito. Estas piezas también narran la anécdota de la mujer del poeta César Vallejo; su viuda siempre decía «cuando César me miraba, no se quedaba en mí, seguía» (Ballesteros, 2008: 47). Por otro lado, poseen dos registros: durante el día afirman la presencia física del cuerpo representado por la figura arrodillada y, por la noche, la energía interna del pensamiento humano emana desde el interior de su cuerpo. De esta forma Plensa explora la dualidad e interrelación entre el interior y el exterior, de nuevo esa idea del cuerpo como cáscara o recipiente "Cada cuerpo es una casa» (Plensa, 2008: 59) y, pese a toda su energía, el pensamiento se encuentra limitado por la materialidad del cuerpo, que se nutre con la energía de la mente (Patrick, 2008: 184). La llarga nit además se inspira directamente en la poesía «Assumiràs la veu d'un poble» de Vicent Andrés Estellés, uno de los grandes poetas valencianos,

Y tú estarás despierto por todos.

No te han parido para dormir:

te parieron para velar en la larga noche de tu pueblo.

Asumirás la voz de un pueblo,

y será la voz de tu pueblo,

y serás, por siempre, pueblo,

y sufrirás, y esperarás,

e irás siempre entre el polvo,

y te seguirá una polvareda.

Y tendrás hambre, y tendrás sed,

no podrás escribir los poemas

y callarás toda la noche mientras duermen tus gentes,

y tú solo estarás despierto

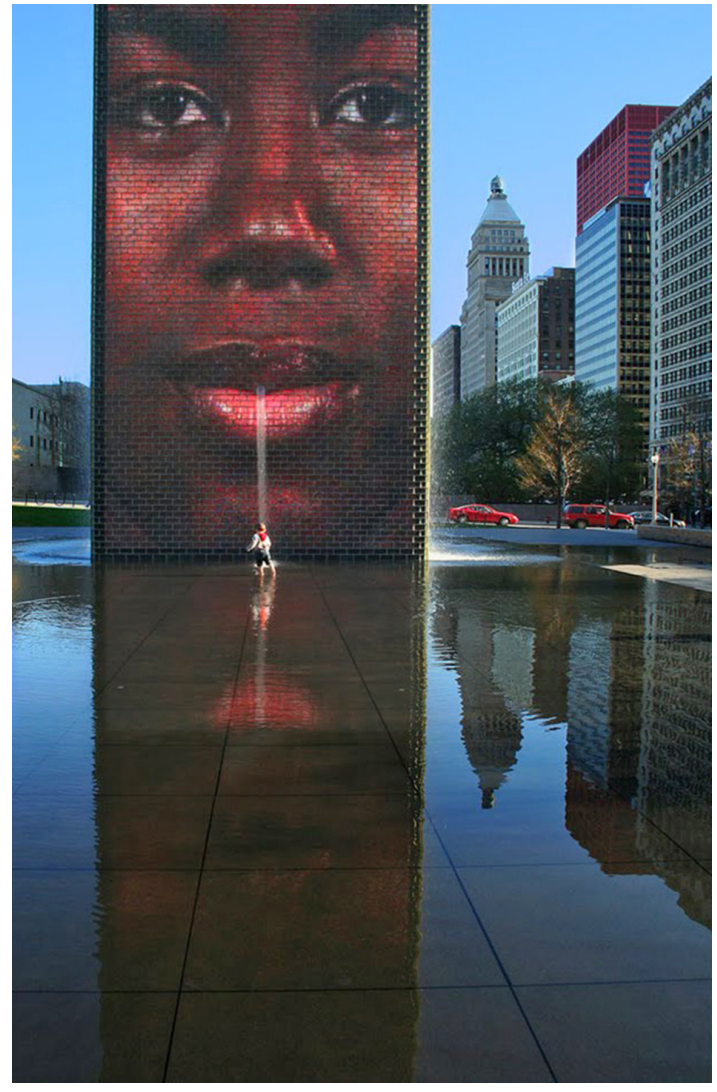

8. J. Plensa, The Crown Fountain, 2004, (C) chicago-outdoorsculptures.blogspot.com. (http://chicago-outdoor-sculptures. blogspot.com.es/2007/09/crown-fountain-millennium-park-v.html)

La figura de las gárgolas también remite al concepto de saliva, en su caso, puesto que eran esculturas que guiaban el agua hacia el exterior del edificio. «Todas las culturas han trabajado en la idea de dar vida a través de la boca, vinculando ésta con la palabra» (Patrick, 2008: 176). Según el autor, gracias a la saliva se desprenden las palabras, a través de las que das vida a los demás (Ballesteros, 2010: 10). Esta idea de dar vida mediante la saliva o la boca se ve claramente traducida en su obra The Crown Fountain, 2004 [8] y asimismo esta figuración de dar vida mediante la saliva o la boca queda patente en sus llamados Hombres de Tel Aviv, 2010 [9]. Estas piezas, construidas a través de la unión de letras, representan el abecedario de todo el mundo. Suelen ser realizadas en grandes dimensiones, con lo que fomentan el tránsito del espectador por su interior. El público, transformado en lector, advierte cómo se mira el mundo a través del 


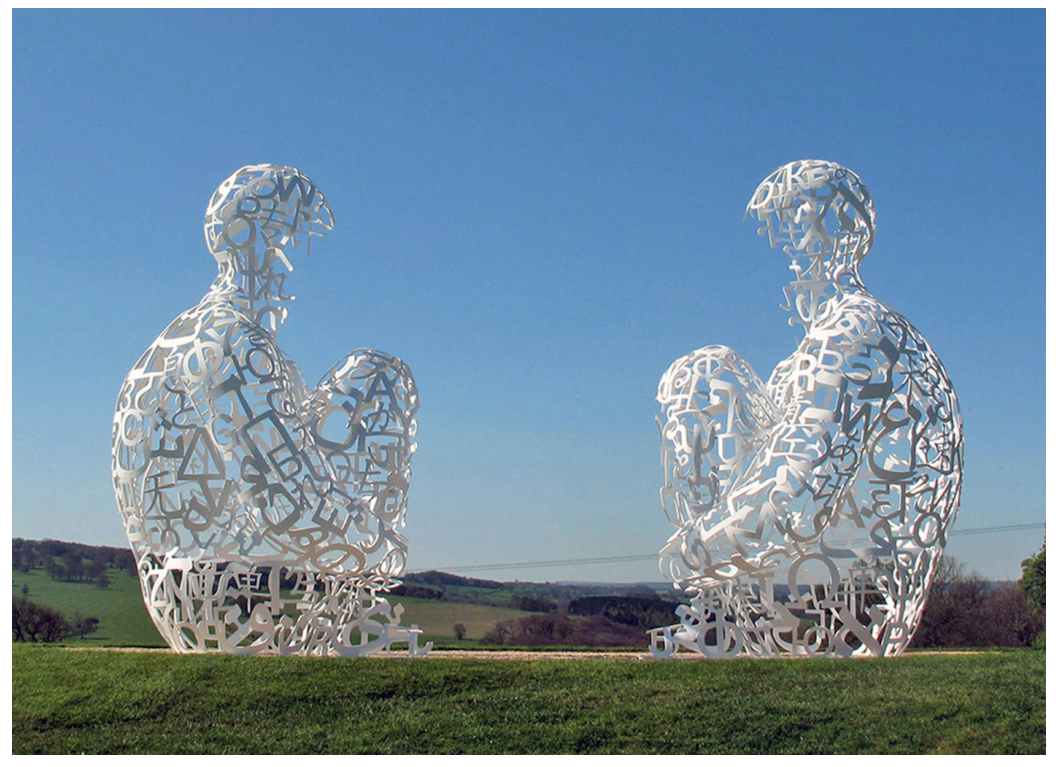

9. J. Plensa, Hombres de Tel Aviv, 2010, (C) Galería Senda (http://galeriasenda. com/artista/jaume-plensa/\#galeria-grid) signo lingüístico, al representar la idea de un hombre a medio construir por sus propias palabras. La fuente literaria de estas piezas se halla en un fragmento de la obra de Rabelais Quart libre des faits et dits heroiques du bon Pantagruel (1552). En ella, se narra que estando Pantagruel en alta mar oyó cómo unas personas hablaban al aire sin que hubiera nadie con ellas. La respuesta a este fenómeno aparece en las primeras líneas del capítulo 55 del libro IV:

Señor no os asustéis. Aquí se hallan los confines del mar de hielo, en el que a principios del invierno pasado tuvo lugar una cruel y gran batalla, en aquella ocasión las palabras, los gritos de los hombres y mujeres se congelaron en el aire, ahora que ya quedó atrás el rigor del invierno con la calma y la serenidad del buen tiempo aquellas se funden y se oyen, las personas recogen un puñado de estas palabras congeladas que parecen grageas perladas de colores, entre sus manos se calientan pero no las entienden porque se trata de un lenguaje de bárbaros.

Estas palabras congeladas son una inspiración fundamental para el autor, que reflexiona sobre esta materialidad de las letras congeladas y pretende hacer de estas un elemento físico, o como él mismo afirma: cuando comencé con estas obras solo pretendía verle la espalda a la «A» (Ballesteros, 2008: 35).
El propio Jaume Plensa (2008: 31) escribe tras leer a Rabelais:

La lentitud al hablar entre capítulos

Como un poeta sin lengua, escucho la dulzura de las ventanas hablando.

Escucho la humedad de la palabra:

Palabras pegajosas, enfermas, congeladas.

Hablo entre tus piernas de velludos arcaísmos: palabras pegajosas, enfermas, congeladas.

Hablo desde hospitales de cosas cotidianas que nos hagan reír y, entre risas, hablar: hablar de un La Tour arcaico, de un Giotto peludo, de un Botticelli enfermo.

Hablo desde hospitales, desde museos inundados de cadáveres.

Tendido como un cadáver, comparto contigo el frío, el silencio.

El reencuentro con países que, entre otros, se han helado.

Tú y yo en la frontera, tendidos, entre otros.

Setenta y tres islas, congeladas, entre otras. 
Además de crear estas esculturas gigantes de figuras humanas, proyecta, gracias al concepto de Rabelais, sus famosas cortinas de letras [10]. Esta alusión a la forma de habitar es constante en la estética de Plensa, como afirma Castro Flores (2007: 47), «a veces con el esquema de muro o barricada». Estas piezas, construidas con finos hilos de alambre, conforman una metáfora de la leyenda de Alicia, al otro lado del espejo, «es la idea de Wonderland, señala Plensa: Alicia no puede encontrar la entrada de inmediato, primero debe transformarse a sí misma para encontrar la puerta, tienen que cambiar de escala para cruzar la puerta detrás de la cortina» (Ballesteros, 2010: 78). Es curioso, sin duda, que el autor remita a esa necesidad de Alicia de empequeñecer para cruzar, puesto que uno de los argumentos a los que recurre el mismo Plensa al vincular con su imaginario estas piezas es la reminiscencia de ese tintineo que emiten las letras cuando cruzamos, que evoca en él su infancia.

Pero al crear estas cortinas con letras, llamadas Twentynine Palms, no solo enfatiza y crea una pieza que representa perfectamente la historia de Rabelais, sino que en ellas recoge textos fundamentales en el imaginario de Plensa: el Cantar de los cantares, la Declaración de los derechos humanos y, por último, poesías de Blake, Dante, Shakespeare, Estellés.

La relación del Cantar de los cantares con la creación de esculturas que separan dos espacios no es la primera vez que es representada por Plensa. De hecho, antes que en las cortinas, la relación de estas obras literarias con la escultura se puede observar en sus cabinas (Taján, 2000: 11). Tanto en unas como en otras remite a la idea de muro, un muro que tiene que cruzar el amante para encontrarse con su amada, pero para Plensa ese amante es el cuerpo que debe cruzar mediante el conocimiento un muro hacia el alma.

\section{Conclusiones}

Una de las contribuciones fundamentales de de Plensa al arte contemporáneo, así como a la escultura, es la materialización del discurso literario a partir de textos canónicos, de textos conocidos, de los que emana la esencia que impregna el espacio que ocupan cada una de las obras de este autor. Como afirma Bruno Corá (1999: 21): «lo que pone de manifiesto el trabajo de Plensa es un nuevo tipo de pathos,

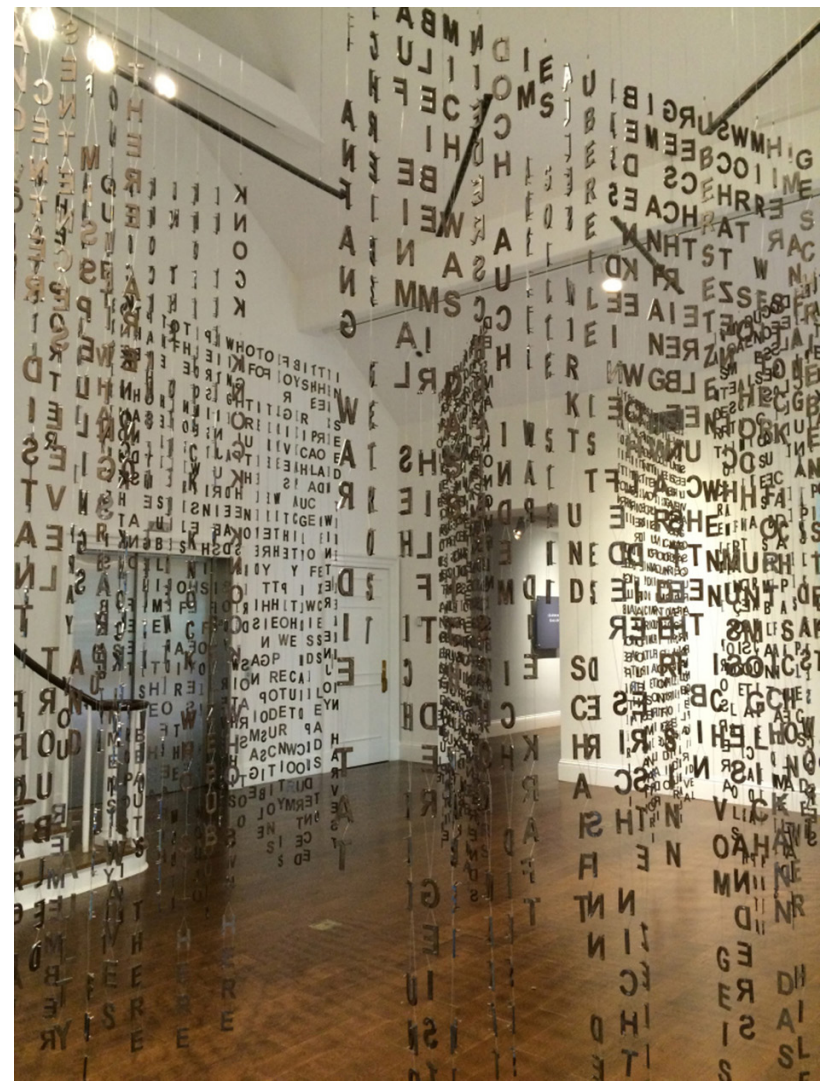

10. J. Plensa, Cortinas de letras, @ tripintheusa https://tripintheusa. com/2016/03/30/jaume-plensa-exhibit-cheekwood-botanical-gardens/)

esto es lo que realmente lo diferencia de sus contemporáneos. No cabe duda que ante nuestros ojos se desarrolla una batalla crucial entre el ser, la existencia y sus símbolos». La palabra invade el espacio al igual que un pensamiento llena la inmensidad gnóstica, mística, de William Blake. Una palabra que surge de la saliva en la boca, como representa en sus obras The Crown Fountain o los Hombres de Tel Aviv, originada fenomenológicamente en una conciencia, en una cabeza desde la que podemos recorrer las rutas más recónditas de nuestro alma, como podemos discernir en sus obras de cabezas de alabastro, en sus cabezas hechas con letras o en sus cabezas con luz.

La obra literaria de otros autores en Plensa, pura transdiscursividad, se transforma, se muta en obra propia, en textos nuevos, diferentes, que él mismo traduce con sus propias palabras y que posteriormente filtrará de una forma tangible en la escultura que recorre el espacio, y va más allá 
de aquello que podemos encontrar en las páginas de un libro o en la propia materia escultórica. Plensa dialoga entre lo pequeño y lo gigante, entre lo colectivo y el individuo, se mueve en ese terreno híbrido, en ese punto de convergencia de las artes: un leve filo donde todo y nada sucede a la vez. Explora la materialización de los modos poéticos de la representación y la consiguiente desmaterialización estética de la estructura de la obra. Por esa razón, la práctica artística de Plensa representa, como afirma William Jeffett (2007: 47) «un modo de pensamiento en término de ambigüedades de la poesía; por lo que puede estar relacionado con la herencia escéptica de la investigación filosófica». Por tanto, Plensa ha puesto en primer plano la idea de que la escultura plantea preguntas en lugar de ofrecer respuestas.

En la introducción de este trabajo, en la que relacionábamos la literatura y el arte, planteamos y ahora concluimos que, frente a una historia de la relación entre ambas disciplinas invasiva, considerando como invasivo el hecho de que la escultura era inundada por la literatura, el caso de Plensa nos permite llevar lo poético a un plano diferente, tridimensional, sin perder la esencia del origen ligüístico. Plensa modifica el material con el que, a priori, se construye la poesía que es la palabra y va un paso más allá, transformando la palabra en cuerpo. Como él mismo afirma: «las palabras son un material. Mi aproximación al texto es física» (2008: 32).

No es tarea sencilla establecer la comparación entre dos mundos distintos, entre dos signos relacionados como la escultura y la literatura. Hemos intentado abordar la transfiguración recíproca de un lenguaje en otro, pero sin quedarnos en la simple comparación, para más bien determinar ese punto intermedio en el que se encuentran gracias a la obra de Plensa. Un autor que expresa abiertamente su amor por la literatura canónica: Wilde, Shakespeare, Blake, Milton, Dante, pero nos invita a que exploremos su trayectoria empírica, personal y subjetiva. La memoria, por tanto, de lo leído será individual y única como un recuerdo de lo vivido, ofreciéndonos un viaje poético hacia el ensimismamiento que nos hace movernos del exterior hacia el interior de nosotros.

\section{Notas}

1 El título de este artículo hace referencia al artículo de Antonio Vigo Pérez «Hacia una escultura escrita para volver a contar y acercar el arte al público escéptico", en la Revista del CES Felipe II, n. ${ }^{13}, 2011$.

\section{Bibliografía}

AGUADO, Jesús (2000), «Fantasmas en la penumbra: el mundo de Jaume Plensa», en AGUADO, Jesús; GARRIDO, Antonio; TAJÁN, Alfredo (2000), Jaume Plensa 360, IML, Málaga, pp. 48-53.

ÁLVAREZ FERNÁNDEZ, Tomás (2015), Obras completas de Santa Teresa de Jesús, Monte Carmelo, Burgos.

BALLESTEROS, Pedro (2010), Jaume Plensa, RTVE, Imprescindibles.

BARONA, Josep Lluís (2006), «Franz Joseph Gall: la frenología y las funciones del cerebro», Mètode: Anuario, n. ${ }^{\circ} 26$, pp. $244-245$.

BLAKE, William (2007), El matrimonio entre el cielo y el infierno, Hiperión, Madrid.

BLESA, Túa (2011), Lecturas de la ilegibilidad en el arte, Delirio, Salamanca.

- (2013), «Escritura sin lectura. La Jalousie de Alain Robbe-Grillet y La Jalousie. Exposición de Simon Zabell, Un ejercicio de ilegibilidad»,

Castilla. Estudios de literatura, n. ${ }^{\circ}$, pp. 581-603.

BLOOM, Harold (1977), La angustia de las influencias, Monte Ávila Editores, Venezuela.

- (2006), El canon occidental, Anagrama, Madrid.

CASTRO FLÓREZ, Fernando (2007), «Jaume Plensa. Habitar en la poesía», Cuadernos del IVAM, n. 11, pp. 44-53.

CATOIR, Barbara (2000), "Chaos-saliva», en AHRENS, Carsten et alii, Chaos-saliva, Museo Nacional Centro de Arte Reina Sofía, Madrid, pp. 127-149.

CíSCAR CASABÁN, Consuelo (2007), «Cuerpos teatralizados», en CíSCAR CASABÁN, Consuelo y WILLIAM, Jeffett, Jaume Plensa, Catálogo IVAM, Valencia, pp. 13-22. 
CORÁ, Bruno (1999), «Sounds and Places of Being», en HEGYL, Löránd et alii, Jaume Plensa, Museum moderner Kunst Stiflung Ludwig Wien, Liechtenstein, pp. 19-26.

— (2005), «Ciudad ideal», en BADIA, Montse; CORÁ, Bruno; TERRASA, Jacques, Jaume Plensa, Catálogo CAC, Málaga, pp. $32-35$.

ELIOT, T.S. (2004), Lo clásico y el talento individual, Universidad Nacional Autónoma de México, México.

FOUCAULT, Michel (1968), Las palabras y las cosas: una arqueología de las ciencias humanas, Siglo XXI, Buenos Aires.

FREEMAN, Kathryn. S. (2016), A Guide to the Cosmology of William Blake, Londres, Routledge.

GABILONDO, Ángel (2000) «Neutro y singular», en ARNALDO, Javier; DUQUE, Félix; GABILONDO, Ángel, Jaume Plensa: Sinónimos, CBA, Madrid, pp. 153-158.

GARRIDO, Antonio (2000), «Metodología de Plensa», en AGUADO, Jesús, GARRIDO, Antonio y TAJÁN, Alfredo (2000), Jaume Plensa 360, IML, Málaga, pp. 6-7.

GUILLÉN, Claudio (2005), Entre lo uno y lo diverso, Tusquets, Barcelona.

HAGSTRUM, Jean. H (1974), The Sister Arts: the Tradition of Literary Pictorialism and English Poetry from Dryden to Gray, University of Chicago Press, Chicago.

HERNÁNDEZ LEÓN, Juan Miguel (2006), «Presentación», en ARNALDO, Javier; DUQUE, Félix; GABILONDO, Ángel, Jaume Plensa: Sinónimos, CBA, Madrid, p. 1.

MATAS PONS, Alejandro (2014), «Lecturas de la ilegibilidad en el arte», $452^{\circ}$ F Revista de Teoría de la Literatura Comparada, n. ${ }^{\circ} 10$, pp. 242-243.

MÉNDEZ BAIGES, Maite (1992), La mirada inútil: la obra de arte en la edad contemporánea, Julio Ollero Editor, Madrid.

MILTON, John (2002), Paraíso perdido, Visión libros, Madrid.

PATRICK, Keith (2008), Jaume Plensa: The Crown Fountain, Hatje Cantz Verlag, Ostfildern.

PLENSA, Jaume (2008), Jaume Plensa. Sombras y textos 1990-2007, Galaxia Gutenberg, Madrid.

PRAZ, Mario (1997), Mnemosyne, Taurus, Madrid.

RENDUELES, César (2007), “Jaume Plensa, la poesía de la materia», Revista Minerva, n. 5, pp. 42-51.

SHAKESPEARE, William (2006), Teatro completo, ilustraciones de Jaume Plensa, Galaxia Gutenberg, Madrid.

TAJÁN, Alfredo (2000), «Los 360 de Jaume Plensa (Fuego de hielo)», en AGUADO, Jesús; GARRIDO, Antonio; TAJÁN, Alfredo (2000), Jaume Plensa $360^{\circ}$, IML, Málaga, pp. 8-12.

TERRASA, Jacques (2005), «Clepsidras y poesía. Reflexiones en torno a una instalación de Jaume Plensa», en BADIA, Montse et alii, Jaume Plensa, Catálogo CAC, Málaga, pp. 36-53.

VILA-MATAS, Enrique (2009), Infinitamente serio, La cámara escrita, Caracas.

VON DRATHEN, Doris y PLENSA, Jaume (2008), Jaume Plensa habla con Doris von Drathen, La Fábrica, Madrid.

WILDE, Oscar (2009), El hombre y la cárcel, INCP, México. 
